\title{
Analisis Pengaruh Dimensi Budaya Terhadap Penggunaan Aplikasi Trasnportasi Online Menggunakan UTAUT2 dan Budaya Hofstede
}

\author{
Thofik Nugroho $^{1}$, Wing Wahyu Winarno², Kholid Haryono ${ }^{1}$ \\ ${ }^{1}$ Fakultas Teknologi Industri, Teknik Informatika, Universitas Islam Indonesia, Yogyakarta, Indonesia \\ ${ }^{2}$ Akuntansi, Sekolah Tinggi Ilmu Ekonomi YKPN, Yogyakarta, Indonesia \\ Email: ${ }^{1} 16917226 @$ students.uii.ac.id, ${ }^{2}$ wing@ @stieykpn.ac.id, ${ }^{3}$ kholid.haryono@uii.ac.id
}

\begin{abstract}
Abstrak-Penting bagi perusahaan aplikasi transportasi online untuk mengetahui faktor yang mempengaruhi penggunaan aplikasi transportasi online. Budaya menjadi faktor yang penting dalam penelitian penerimaan penggunaan teknologi. Penelitian ini menggunakan model penelitian UTAUT2 dan dimensi budaya Hofstede. Tujuan utama penelitian ini akan menginvestigasi bahwa budaya mempengaruhi pengguna dalam menggunakan aplikasi transportasi online. Metode pengukuran menggunakan PLS SEM. Terbukti bahwa budaya mempengaruhi penggunaan aplikasi transportasi online. Hal ini terbukti bahwa dengan menambahkan dimensi budaya dalam model UTAUT2 dapat menjelaskan perilaku penggunaan aplikasi transportasi online lebih baik.
\end{abstract}

Kata Kunci: Aplikasi Transportasi Online, Budaya, Dimensi Budaya Hofstede, PLS SEM, UTAUT2

Abstract-It is important for online transportation application company to know the factors that influence the use of online transportation applications. Culture is an important factor in research into the acceptance of technology use. This study uses the UTAUT2 research model and Hofstede's cultural dimensions. The main objective of this research will be to investigate that culture influences users in using online transportation applications. The measurement method uses PLS SEM. It is proven that culture influences the use of online transportation applications. It is proven that by adding the cultural dimension in the UTAUT2 model, it can better explain the behavior of using online transportation applications.

Keywords: Online Transportation Application, Culture, Hofstede Cultural Dimensions, PLS SEM, UTAUT2

\section{PENDAHULUAN}

Pengembangan Aplikasi seringkali ditujukan untuk pengguna global. Beberapa aplikasi yang dibangun ditujukan untuk pengguna global antara lain sistem operasi, word processor dan Enterprise Resource Management (ERP). Tidak mudah untuk seluruh aplikasi dapat diterima oleh masyarakat global. Hal yang paling utama adalah penggunaan bahasa,warna dan jenis huruf dalam aplikasi.

Aplikasi yang digunakan secara global dipengaruhi oleh beberapa faktor seperti kemudahan penggunaan dan kebermanfaatan. Aplikasi yang digunakan secara global penting diketahui adanya pengaruh budaya terhadap penerimaan dan penggunaan [1].

Budaya adalah suatu pemrograman kolektif yang membedakan individu dari suatu kelompok dengan individu kelompok lain [2]. Pengertian ini menunjukan individu suatu kelompok dengan individu kelompok lain akan berbeda pandangan terhadap suatu objek.

Penerimaan sistem informasi dengan memasukkan budaya telah diteliti sebelumnya. Beberapa penelitian menunjukkan budaya berpengaruh dalam penerimaan dan penggunaan sebuah aplikasi yang digunakan secara global. Penelitian aplikasi mobile banking di Afrika yang memasukkan dimensi budaya dalam pengukurannya telah berhasil menunjukkan bahwa dimensi budaya berpengaruh signifikan [3]. Penelitian tentang penerimaan dan penggunaan email di negara Jepang, Swiss dan Amerika Serikat [1] menunjukkan budaya memiliki peran dalam keberhasilan penggunaannya. Penelitian perancangan tentang antar muka website yang juga dipengaruhi oleh dimensi budaya [4].

Kegagalan dalam menerapkan sebuah sistem informasi salah satunya adalah tidak memperhatikan dimensi budaya. Uber di Tiongkok gagal berkembang dan akhirnya diakuisisi oleh perusahaan Didi (aplikasi transportasi online di Tiongkok) karena salah satunya gagal menggunakan dimensi budaya dalam penerapan operasional aplikasinya [5]. Kegagalan karena tidak bisa menyesuaikan strategi operasional dalam budaya Tiongkok yang lebih menyukai aplikasi lokal. Backfence adalah sebuah perusahaan startup berbentuk website jurnalisme warga yang gagal karena konten terlalu lokal [6]. Eachnet adalah ecommerce yang diakuisisi oleh Ebay untuk melebarkan bisnisnya di China. Eachnet gagal karena gagal memahami kebudayaan dari masyarakat China dalam menggunakan ecommerce[7]. Food Panda Indonesia adalah sebuah startup yang beroperasi untuk layanan jasa antar pesanan makanan yang akhirnya tutup pada 30 September 2016 penyebabnya adalah gagal memahami budaya Indonesia dalam pemesanan makanan. Food Panda adalah starup yang didukung perusahaan luar negeri Rocket Internet yang dirancang hanya untuk pengiriman pesanan makanan jarak dekat dan dengan jumlah tertentu. Hal ini dinilai tidak sesuai dengan budaya di Indonesia.

Aplikasi transportasi online adalah aplikasi yang dibuat oleh perusahaan transportasi online yang ditujukan untuk mempermudah penggunaan jasa transportasi dalam masyarakat dengan menggunakan teknologi berbasis internet. Aplikasi transportasi online adalah salah satu aplikasi yang ditujukan untuk penggunaan global (penggunanya lintas negara). Gojek dan Grab adalah aplikasi transportasi online yang sekarang mendominasi di Indonesia dan ASEAN. Sebelumnya ada perusahaan Uber Indonesia tetapi telah bergabung dengan Grab 
Indonesia. Beberapa perusahaan transportasi berbasis online yang lain adalah blueJek, TeknoJek, LadyJek dan aplikasi lainnya.

Menurut penelitian Baptista tahun 2015 menyebutkan bahwa budaya lokal mempengaruhi akan penerimaan sebuah teknologi. Indonesia negara dengan ragam budaya yang besar dan nilai kolektivitas yang cukup tinggi. Hal ini dapat menjadi dasar budaya seharusnya menjadi salah satu dasar pengukuran penerimaan teknologi.

Menurut Hofstede sebuah sistem atau aplikasi yang dibangun dan digunakan di berbagai tempat dan menglobal harus memperhatikan dimensi budaya dalam pengukuran adopsi dan keberhasilan dalam penggunaannya. Hal ini menjadi penting bagi negara dengan ragam budayanya cukup banyak.

Penelitian tentang penerimaan teknologi informasi melibatkan dimensi budaya masih sedikit dilakukan di negara berkembang khususnya Indonesia [8]. Hal ini penting dilakukan penelitian untuk mengetahui apakah dimensi budaya memiliki pengaruh terhadap penggunaan dan penerimaan aplikasi transportasi online. Dan diharapkan penelitian ini dapat memberikan prediksi lebih kuat terhadap penerimaan dan penggunaan aplikasi transportasi online dibanding dengan penelitian sebelumnya. Penggunaan Dimensi budaya dalam evaluasi penerimaan dan penggunaan transportasi online diharapkan dapat menemukan pandangan baru untuk mengetahui perilaku individu yang dipengaruhi oleh budaya [3].

Model Penelitian evaluasi penerimaan dan penggunaan ICT (Information and Communication Technology) untuk negara maju dan negara berkembang adalah berbeda hal ini karena pengaruh budaya [8]. Kepercayaan dan nilai yang dibagi dalam sebuah komunitas dapat mempengaruhi perilaku seseorang dalam perubahan penggunaan teknologi [9].Hal ini memperkuat untuk diadakannya penelitian memasukan dimensi budaya dalam evaluasi penerimaan dan penggunaan aplikasi transportasi online.

Penelitian ini akan memasukkan dimensi budaya terhadap perilaku penggunaan aplikasi transportasi online dengan studi kasus Gojek dan Grab. Hasil dari penelitian ini diharapkan bisa memberikan gambaran pengaruh kebudayaan terhadap penggunaan aplikasi transportasi online. Kontribusi pada penelitian ini ditujukan kepada para praktisi atau operator aplikasi transportasi online dan juga bagi pengetahuan. Bagi operator hasil penelitian ini bisa digunakan untuk mendesain ulang, melakukan perbaikan pada aplikasi dan juga mendesain ulang strategi pemasarannya serta cara berkomunikasi yang efektif untuk mendapatkan nilai penerimaan yang lebih baik untuk setiap daerah yang akan menjadi target pemasaran. Bagi ilmu pengetahuan hal ini dapat diketahui bahwa dimensi budaya semakin penting dimasukan dalam evaluasi sebuah sistem informasi atau aplikasi yang digunakan secara luas atau global.

Penelitian ini memiliki tujuan untuk mengetahui apakah dimensi budaya mempengaruhi penggunaan aplikasi transportasi online. Penelitian ini juga memiliki tujuan untuk mengetahui peran dimensi budaya hofstede dalam tingkat penerimaan aplikasi transportasi online. Pada penelitian ini mengambil studi kasus Propinsi Daerah Istimewa Yogyakarta.

\section{METODE PENELITIAN}

\subsection{Model Penelitian}

Model penerimaan teknologi informasi pada negara maju berbeda dengan negara berkembang khususnya dalam dimensi budaya [8]. Penerimaan teknologi di era globalisasi berbeda di setiap negara hal ini bergantung pada budaya yang melekat pada negara tersebut. Dimensi budaya menjadi penting dalam menunjukkan perilaku penggunaan teknologi informasi [1] untuk digunakan membuat evaluasi penerimaan di negara dengan nilai kolektivitas tinggi.

Penerimaan sebuah teknologi dari beberapa komunitas atau group lokal dengan berbeda budaya menghasilkan penerimaan yang berbeda [3]. Hal ini memperkuat bahwa dimensi budaya seharusnya dimasukan dalam konstruk penerimaan dan pengukuran pengaruh dalam penggunaan teknologi yang ditujukan untuk pengguna global. Oleh karena itu penelitian ini akan memasukan dimensi budaya untuk melakukan investigasi lebih lanjut tentang penerimaan dan penggunaan aplikasi transportasi online.

Pada penelitian ini menggunakan enam dimensi budaya Hofstede yaitu Power Distance,Individualism vs Collectivism, Masculinity vs Feminimity,Uncertainty Avoidance,Long Term vs Short Term Orientation dan Indulgence vs Restraint. Dimensi budaya Hofstede telah banyak digunakan dalam penelitian.

Beberapa penelitian menunjukan dimensi budaya Hofstede [1], [3], [4], [8] telah luas pengaruhnya pada penelitian sebelumnya. Untuk peneitian penerimaan sebuah teknologi informasi negara-negara dengan tingkat kolektivitasnya tinggi telah banyak memasukan dimensi budaya hofstede.Penelitian ini dengan studi kasus di Indonesia dengan budaya yang beragam akan menggunakan dimensi budaya Hofstede dan studi kasus penerimaan dan penggunaan Sistem Transportasi online. Gambar 1 menunjukan model yang akan digunakan dalam penelitian ini yaitu menggabungkan model penelitian UTAUT2 dan dimensi budaya Hofstede. 


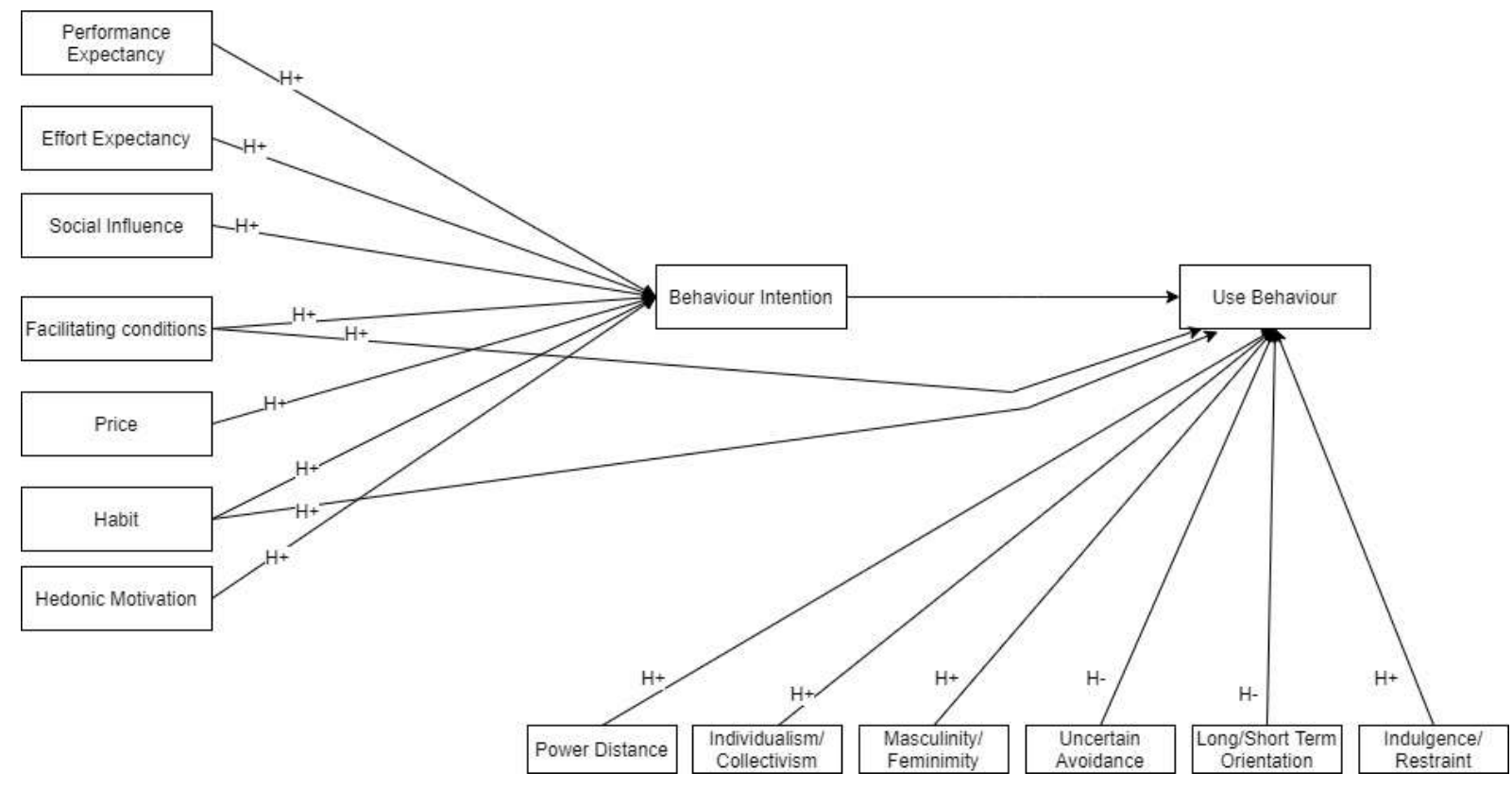

Gambar 1. Model Penelitian UTAUT2 dan Budaya Hofstede

Desain Indikator dan kuesioner untuk UTAUT2 menggunakan indikator yang digunakan oleh Venkatesh (2012)[10] dan disesuaikan dengan objek penelitian yaitu pengguna aplikasi transportasi online. Sedangkan untuk indikator dimensi budaya menggunakan indikator dari penelitian Srite \& Karahanna (2006)[11] dan Hassan et al (2011) [12] yang disesuaikan dengan bahasa dan objek penelitian. Variabel Indulgence/ Restraint (IR) menggunakan indicator yang dibuat oleh peneliti. Dalam memberikan tanggapan dari kuesioner para partisipan mengisikan dengan memilih skala Likert mulai dari 1 (sangat tidak setuju) sampai 5 (sangat setuju).

\subsection{Penentuan Sampel dan Pengumpulan Data}

Penelitian ini menggunakan metode positivistik dengan data kuantitatif. Penelitian ini menggunakan metode kuisioner untuk mendapatkan data yang kemudian digunakan untuk melakukan analisis terhadap temuan. Objek penelitian adalah pengguna transportasi online di Daerah Istimewa Yogyakarta. Penelitian ini menggunakan metode pengukuran dan analisis PLS SEM, jumlah sampel data yang dibutuhkan adalah 10 kali jumlah indikator terbanyak yang membentuk sebuah variabel [13]. dalam penelitian ini jumlah indikator terbanyak adalah 4 indikator jadi minimal jumlah sampel data adalah 40 .

\subsection{Hipotesis}

Dari hasil studi pustaka dalam penelitian ini akan dibangun beberapa hipotesis sesuai dengan model yang telah dibangun. Hipotesis kemudian akan diujikan dan dianalisis dengan metode PLS SEM.

H1: Performance Expectancy (PE) akan berpengaruhi positif terhadap Behavioural Intention (BI)

Harapan kinerja (performance expectation) adalah tingkat seseorang atau individu percaya bahwa menggunakan teknologi akan memberikan manfaat [14]. Hal itu menunjukkan seseorang akan menggunakan teknologi jika mereka yakin akan mendapatkan hasil positif setelah memakainya [15]. menggunakan teknologi pada dasarnya membantu seseorang karena manfaat yang akan didapatkan. Harapan kinerja diharapkan menjadi salah satu faktor terpenting itu langsung mempengaruhi niat penerimaan.

H2: Effort Expectancy (EE) akan berpengaruh positif terhadap Behavioural Intention (BI)

Harapan usaha (effort expectation) adalah tingkat kemudahan penggunaan teknologi bagi penggunanya [14]. Aplikasi transportasi online akan lebih penggunnya jika mudah untuk digunakan untuk semua umur yang menjadi target. Kemudahan bisa dari sisi desain menu aplikasi atau fasilitas untuk menggunakannya. Hal ini menunjukan bahwa Harapan usaha kemungkinan akan mempengaruhi kuat terhadap niat penggunaan.

H3: Social Influence (SI) akan berpengaruh positif terhadap Behavioural Intention (BI)

Pengaruh sosial (social influence) adalah sejauh mana seseorang merasakan bahwa penggunaan teknologi itu akan dipengaruhi orang lain terutama keluarga dan teman [14]. Pada penelitian terdahulu para peneliti menemukan bahwa pengaruh sosial, meskipun berbeda istilah yang digunakan dalam penelitian mereka, memiliki pengaruh signifikan hubungan dengan niat perilaku. Hal ini menunjukan bahwa seseorang menggunakan aplikasi transportasi online karena ada pengaruh orang lain.Pengaruh social kemungkinan akan memperkuat seseorang berniat untuk menggunakan aplikasi transportasi online.

H4a: Facilitating Condition (FC) akan berpengaruh positif terhadap Behavioural Intention (BI)

H4b: Facilitating Condition (FC) akan berpengaruh positif terhadap Use Behaviour(UB) 
Kondisi fasilitasi (facilitating condition) ditunjukan bahwa seseorang percaya adanya infrastruktur atau fasilitas yang akan memudahkan mereka untuk menggunakan sebuah teknologi [10]. fasilitas infrastruktur jaringan yang tersedia, hal ini membuat pengguna aplikasi nyaman dalam menggunakannya dan dapat selalu menggunkan saat dibutuhkan. Fasilitas lainnya yang bisa disediakan oleh Perusahaan aplikasi transportasi daraing adalah tutorial penggunaan atau petugas yang bisa memberikan bantuan dalam penggunaannya. Kondisi fasilitas kemungkinan akan mempengaruhi niat dan perilaku penggunaan aplikasi transportasi online.

H5: Hedonic Motivation (HM) akan berpengaruh positif terhadap Behavioural Intention (BI)

Motivasi hedonis (hedonic motivation) adalah tingkat kesenangan atau kesenangan yang diperoleh

dalam menggunakan sebuah teknologi [10]. Motivasi hedonis merupakan faktor penting dalam penerimaan teknologi pengguna. Hal ini menunjukan motivasi hedonis kemungkinan akan memperkuat seseorang untuk berniat menggunakan aplikasi transportasi online.

H6: Price Value (PV) akan berpengaruh positif terhadap Behavioural Intention (BI)

Nilai harga (price value) adalah manfaat yang dirasakan pengguna dari penggunaan teknologi dengan biaya yang dikeluarkan [10]. nilai harga akan dianggap bernilai ketika manfaat menggunakan aplikasi transportasi dianggap lebih besar dari biaya yang dikeluarkan. Nilai harga kemungkinan akan memperkuat seseorang akan berniat menggunakan aplikasi transportasi online.

H7a: Habit (HB) akan berpengaruh positif terhadap Behavioural Intention (BI)

H7b: Habit (HB) akan berpengaruh positif terhadap Use Behaviour(UB)

Kebiasaan akan terlihat dari hasil pengalaman sebelumnya [10]. Kebiasaan adalah frekuensi perilaku masa lalu dianggap sebagai salah satu penentu utama perilaku saat ini [16]. Kebiasaan akan pengalaman penggunaan aplikasi transportasi online kemungkinan akan memperkuat niat seseorang menggunakan aplikasi transportasi online

H8: Behavioural Intention (BI) akan berpengaruh positif terhadap Use Behaviour(UB)

Bedasarkan teori psikologi, yang berpendapat bahwa perilaku individu dapat diprediksi dan dipengaruhi oleh niat individu [17]. Pada model UTAUT2 menyatakan dengan kuat bahwa niat perilaku memiliki pengaruh besar tentang penggunaan teknologi [14].

H9: Individualism/Collectivism (IC) akan berpengaruh positif terhadap Use Behaviour (UB) Seseorang dalam budaya individualis akan lebih mementingkan diri sendiri daripada dengan kelompoknya. Orang yang memegang nilai-nilai kolektivis lebih mempedulikan kebersamaan kelompok dan menghargai pendapat orang lain tentang teknologi . Di negara-negara kolektivistik lebih cenderung mengadopsi teknologi baru atau layanan [2].

H10: Uncertainty Avoidance (UA) akan berpengaruh negatif terhadap Use Behaviour (UB)

Budaya dengan tingkat penghindaran ketidakpastian (uncertainty avoidance) yang tinggi akan memiliki tingkat penerimaan teknologi yang rendah karena penggunaan teknologi bisa mengandung ketidakpastian dibandingkan dengan fasilitas lainnya[1] .Orang yang menghindari ketidakpastian merasa tidak nyaman dengan ketidakpastian dan tidak mudah menggunakan teknologi. Di negara yang nilai penghindaran ketidakpastian rendah orang cukup santai dan suka mengambil risiko [18] dan akan lebih mungkin untuk mencoba sesuatu yang baru atau mengadopsi sebuah teknologi IT [19]. Penghindaran ketidakpastian akan kemungkinan memperlemah seseorang akan menggunakan aplikasi transportasi online

H11: Long/Short Term Orientation (LT) akan berpengaruh negatif terhadap Use Behaviour (UB)

Orang yang memiliki Orientasi jangka panjang(long term orientation) akan memiliki kepercayaan dan perilaku seperti penghematan atau ketekunan untuk tujuan masa depan [20].Masyarakat yang memiliki orientasi jangka panjang akan cenderung tidak akan mencoba teknologi baru berbanding terbalik dengan negara dengan orientasi jangka pendek [18]. Masyakat yang memiliki orientasi jangka panjang kemungkinan akan memperlemah seseorang akan menggunakan aplikasi transportasi online.

H12: Masculinity/Femininity (MF) akan berpengaruh positif terhadap Use Behaviour (UB)

Pada masyarakat maskulin terdapat sifat yang senang akan tantangan,penghasilan, ketegasan, ambisi, dan berurusan dengan fakta adalah faktor paling bernilai [21]. Hal ini menunjukan masyarakat maskulin akan lebih mudah menerima teknologi baru karena ada fakta dan tantangan dalam penggunaan teknologi baru. Masyarakat yang maskulin kemungkinan akan memperkuat orang dalam menggunakan aplikasi transportasi online.

H13: Power Distance (PD) akan berpengaruh positif terhadap Use Behaviour (UB) Dalam masyarakat hierarkis orang akan cenderung patuh dengan pendapat atasan mereka dan takut tidak setuju dengan atasannya [2]. Hierarki dipandang mencerminkan ketidaksetaraan, sentralisasi , dan bawahan berharap untuk diberi tahu apa yang harus dilakukan [18]. Jika atasan atau orang yang berkuasa atas dirinya dalam sebuah pekerjaan menggunakan teknologi dan merekomendasikan untuk menggunakannya maka kemungkinan besar seseorang juga akan menggunakan.

H14: Indulgence/ Restraint (IR) akan berpengaruh positif terhadap Use Behaviour (UB)

Dalam masyarakat yang memberi kesenangan atau kebebasan (Indulgence) pada anggotanya menunjukkan dalam masyarakat yang sangat toleransi dalam pengekspresian hasrat dan perasaan terutama dalam pemanfaatan waktu luang, mencari hiburan bersama teman, pemberian barang, konsumsi dan sampai pada hal-hal berkaitan dengan seksual. Sedangkan restraint menunjukkan masyarakat membatasi atas kesenangan- 
kesenangan anggotanya [22]. masyarakat yang memberi kebebasan dan kesenangan kemungkinan akan memperkuat seseorang untuk menggunakan aplikasi transportasi online. Hal ini karena adanya kebebesan dalam memilih sesuatu untuk kesenangan seseorang akan mempengaruhi penggunaan teknologi.

\section{HASIL DAN PEMBAHASAN}

\subsection{Gambaran Umum Responden}

Penelitian ini dilakukan di wilayah propinsi Daerah Istimewa Yogyakarta. Penelitian dilakukan dengan cara melakukan survei online yang dilakukan selama bulan februari 2020. Responden yang mengikuti survei sebanyak 89 peserta sedangkan data yang dapat digunakan dan valid terdapat 73 data. Data yang tidak digunakan karena pengisian kuisioner dari peserta tidak lengkap dan hanya mengisi dengan pilihan tertentu.

Penelitian ini menggunakan metode pengukuran PLS SEM dengan menggunakan software SmartPLS. Jumlah responden sudah mencukupi minimal dengan metode PLS[13].

Tabel 1. Data Demografi

\begin{tabular}{|c|c|c|}
\hline Data Demografi & Jumlah & $\%$ \\
\hline \multicolumn{3}{|l|}{ Jenis Kelamin } \\
\hline Perempuan & 31 & 42 \\
\hline Laki-laki & 42 & 58 \\
\hline \multicolumn{3}{|l|}{ Pendidikan } \\
\hline SMA & 18 & 25 \\
\hline D3 & 4 & 5 \\
\hline $\mathrm{S} 1$ & 45 & 62 \\
\hline $\mathrm{S} 2$ & 6 & 8 \\
\hline \multicolumn{3}{|l|}{ Umur } \\
\hline$<20$ tahun & 4 & 5 \\
\hline 20-30 tahun & 40 & 55 \\
\hline 30-40 tahun & 22 & 30 \\
\hline >40tahun & 7 & 10 \\
\hline
\end{tabular}

\subsection{Analisis Data}

Data penelitian yang telah dikumpulkan dilakukan analisis untuk membuktikan hipotesis. Data dinalisis dengan metode PLS SEM dengan menggunakan Software SmartPLS. Metode PLS dilakukan dua tahap yaitu model pengukuran (evaluasi outer model) dan model struktural (evaluasi inner model).

\subsubsection{Evaluasi Outer Model (Model Pengukuran)}

Pada tahap evaluasi outer model akan dilakukan uji validitas dan reabilitas. Uji validitas mengukur setiap indikator yang menyusun suatu variabel. Sedangkan uji reabilitas menguji variabel yang menyusun model.

Uji validitas dilakukan dengan mengukur nilai factor loading (FL) dan cross loading setiap indikator. Nilai factor loading dari setiap indikator yang digunakan untuk analisis $\mathrm{FL} \geq 0.5$ sedangkan nilai cross loading setiap indikator harus lebih besar dari nilai cross loading pada variabel atau konstruk lainnya [13], [23]. Pada pengukuran factor loading awal indikator PD3,PD4 dan IR3 memiliki nilai dibawah 0,5. Hal ini mengakibatkan indikator PD3,PD4 dan IR3 harus dihapus untuk membuat model valid. Selanjutnya dilakukan pengukuran ulang untuk factor loading hasilnya seperti tabel di bawah dan tidak ada indikator yang factor loading dibawah 0,5 nilainya. Pengujian validitas outer model selanjutnya adalah melihat cross loading dari indikator terhadap seluruh variabel atau konstruk yang ada. Nilai loading indikator terhadap variabelnya harus lebih besar dari nilai loading indikator terhadap variabel lainnya [23]. Pada pengujian cross loading semua indikator memenuhi kriteria.

Tabel 2. Factor Loading

\begin{tabular}{ll}
\hline Indikator & $\begin{array}{l}\text { Factor } \\
\text { Loading }\end{array}$ \\
\hline PE1 & 0.978 \\
PE2 & 0.991 \\
PE3 & 0.932 \\
PE4 & 0.978 \\
EE1 & 0.660 \\
EE2 & 0.884 \\
EE3 & 0.820 \\
EE4 & 0.894
\end{tabular}

\begin{tabular}{ll}
\hline Indikator & $\begin{array}{l}\text { Factor } \\
\text { Loading }\end{array}$ \\
\hline PV1 & 0.869 \\
PV2 & 0.866 \\
PV3 & 0.902 \\
PV4 & 0.831 \\
HB1 & 0.912 \\
HB2 & 0.905 \\
HB3 & 0.895 \\
HB4 & 0.958
\end{tabular}

\begin{tabular}{ll}
\hline Indikator & $\begin{array}{l}\text { Factor } \\
\text { Loading }\end{array}$ \\
\hline UA2 & 0.823 \\
UA3 & 0.823 \\
UA4 & 0.623 \\
LT1 & 0.904 \\
LT2 & 0.755 \\
LT3 & 0.812 \\
LT4 & 0.697 \\
MF1 & 0.718
\end{tabular}


JURNAL MEDIA INFORMATIKA BUDIDARMA

Volume 4, Nomor 2, April 2020, Page 377-385

ISSN 2614-5278 (media cetak), ISSN 2548-8368 (media online)

Available Online at https://ejurnal.stmik-budidarma.ac.id/index.php/mib DOI 10.30865/mib.v4i2.2062

$\begin{array}{llllll}\text { SI1 } & 0.741 & \text { BI1 } & 0.964 & \text { MF2 } & 0.823 \\ \text { SI2 } & 0.953 & \text { BI2 } & 0.975 & \text { MF3 } & 0.775 \\ \text { FC1 } & 0.959 & \text { BI3 } & 0.969 & \text { MF4 } & 0.719 \\ \text { FC2 } & 0.956 & \text { UB } & 1.000 & \text { PD1 } & 0.808 \\ \text { FC3 } & 0.942 & \text { IC1 } & 0.731 & \text { PD2 } & 0.923 \\ \text { FC4 } & 0.962 & \text { IC2 } & 0.957 & \text { IR1 } & 0.987 \\ \text { HM1 } & 0.896 & \text { IC3 } & 0.951 & \text { IR2 } & 0.720 \\ \text { HM2 } & 0.952 & \text { IC4 } & 0.956 & & \end{array}$

UA1 0.788

Pengukuran outer model selanjutnya adalah uji reabilitas. Pada pengujian reabilitas ada beberapa kriteria yang harus dipenuhi yaitu nilai Cronbach's Alfa $(\mathrm{CA})>0.6$ nilai Composite Reability $(\mathrm{CR})>0,6$ serta nilai Average Variance Extracted(AVE) > 0,5. Nilai CA dan CR dapat dilihat pada tabel di bawah.

Tabel 3. Cronbach's Alfa, CR dan AVE

\begin{tabular}{lrrr}
\hline Variabel & Conbach's Alfa & CR & AVE \\
\hline PE & 0.979 & 0.985 & 0.941 \\
EE & 0.841 & 0.890 & 0.672 \\
SI & 0.668 & 0.841 & 0.728 \\
FC & 0.968 & 0.976 & 0.912 \\
HM & 0.901 & 0.938 & 0.836 \\
PV & 0.890 & 0.924 & 0.752 \\
HB & 0.937 & 0.955 & 0.842 \\
BI & 0.968 & 0.979 & 0.941 \\
UB & 1.000 & 1.000 & 1.000 \\
IC & 0.931 & 0.946 & 0.817 \\
UA & 0.770 & 0.851 & 0.591 \\
LT & 0.827 & 0.872 & 0.633 \\
MF & 0.763 & 0.801 & 0.577 \\
PD & 0.684 & 0.858 & 0.753 \\
IR & 0.748 & 0.851 & 0.746 \\
\hline
\end{tabular}

Dari hasil pengukuran menunjukan bahwa semua variabel memenuhi uji reabilitas. Pengukuran outer model telah memenuhi uji validitas dan reabilitas hal ini menunjukan bahwa pengukuran selanjutnya untuk Inner Model dapat dilakukan.

\subsubsection{Evaluasi Inner Model (Model Struktural)}

Pengukuran model struktural atau Inner model dilakukan bertujuan untuk melihat hubungan antara variabel dalam model serta untuk menguji hipotesis yang telah ditetapkan. Pada pengukuran model struktural ini akan melihat nilai Pvalue dengan nilai signifikansi Pvalue $<0,1$ (cukup signifikan), Pvalue $<0.05$ (signifikan) dan Pvalue $<0,01$ (sangat signifikan). Pengukuran menggunakan PLS akan menggunakan bootstrap resampling untuk mendapatkan nilai Pvalues dengan 500 iterasi untuk resampling dengan menggunakan software SmartPLS.

Pada pengukuran model struktural melihat hubungan variabel dengan melihat nilai path cofficients. Nilai positif dari path cofficient menunjukan hubungan positif antar variabel sedangkan untuk nilai path cofficient negatif menunjukan hubungan negatif antar variabel. Nilai Pvalue dan path cofficient dapat dilihat pada tabel di bawah.

Tabel 4. Hasil Pengukuran Inner Model

\begin{tabular}{lrrll}
\hline Konstruk & Pvalues & Path Coefficients & signifikan & Hasil Hipotesis \\
\hline H1: PE -> BI & 0.085 & 0.149 & $*$ & diterima \\
H2: EE -> BI & 0.472 & -0.05 & & ditolak \\
H3: SI -> BI & 0.685 & 0.041 & & ditolak \\
H4a: FC -> BI & 0.279 & 0.099 & & ditolak \\
H4b: FC -> UB & 0.02 & -0.28 & $* *$ & ditolak \\
H5: HM -> BI & 0.03 & 0.213 & $* *$ & diterima \\
H6: PV -> BI & 0.842 & 0.018 & & ditolak \\
H7a: HB -> BI & 0 & 0.563 & $* * *$ & diterima \\
H7b: HB -> UB & 0.496 & 0.133 & & ditolak \\
H8: BI -> UB & 0.073 & -0.187 & $*$ & diterima \\
H9: IC -> UB & 0.772 & -0.031 & & ditolak \\
H10: UA -> UB & 0.007 & 0.314 & $* *$ & ditolak
\end{tabular}


ISSN 2614-5278 (media cetak), ISSN 2548-8368 (media online)

Available Online at https://ejurnal.stmik-budidarma.ac.id/index.php/mib DOI $10.30865 /$ mib.v4i2.2062

\begin{tabular}{lrrll} 
H11: LT -> UB & 0.002 & -0.405 & $* *$ & ditolak \\
H12: MF -> UB & 0.129 & -0.192 & & ditolak \\
H13: PD -> UB & 0.073 & 0.256 & $*$ & ditolak \\
H14: IR -> UB & 0.011 & 0.509 & $* *$ & diterima \\
\hline
\end{tabular}

Pada pengujian hipotesis terdapat lima yang diterima yaitu PE -> BI, HM $\rightarrow$ BI, HB -> BI, BI $\rightarrow$ UB dan IR ->UB. Pada pengujian terdapat satu dimensi budaya IR yang mempengaruhi UB dengan positif dan signifikan. Hal ini menunjukan bahwa terdapat dimensi budaya yang mempengaruhi penggunaan aplikasi transportasi online.

Pada hasil pengujian terdapat dimensi budaya Hofstede yang berpengaruh signifikan tetapi berbeda dengan hipotesis yaitu. IC -> UB, LT -> UB dan PD -> UB. Hal ini menunjukan bahwa penelitian ini tidak bisa membuktikan hipotesis yang telah dibuah dan menunjukan kebalikannya.

aplikasi yang sudah jadi dan kemudian digunakan oleh target penggunanya. Perusahaan aplikasi transportasi online yang digunakan dalam penelitian ini baik Gojek dan Grab telah berhasil menjadikan aplikasi transportasi onlinenya membantu para penggunanya untuk memudahkan dalam menggunakan alat transportasi. Hal ini menunjukan manfaat besar yang dirasakan para pengguna setelah menggunakan aplikasi trasnportasi online.

Faktor motivasi mencari kesenangan (hedonic motivation) terbukti menjadi salah satu faktor yang menjadikan seseorang berniat untuk menggunakan aplikasi transportasi online. Hal ini pengguna merasa senang ketika menggunakan layanan aplikasi transportasi online yang memudahkan. Transportasi online membuat penggunanya merasa senang dalam menggunakannya.

Faktor kebiasaan (habit) terbukti menjadi salah satu faktor yang menjadikan seseorang berniat menggunakan aplikasi trasnportasi online. Hal ini menunjukan bahwa pengguna telah menjadi kebiasaan dalam menggunakan layanan aplikasi transportasi online. Aplikasi transportasi online mulai digunakan di indonesia pada tahun 2010 dimulai dengan beroperasinya aplikasi transportasi online Gojek. Hal ini menunjukan bahwa penggunaan transportasi telah menjadi kebiasaan bagi penggunanya.

Penelitian ini harapan usaha (effort expectation), pengaruh sosial (social influence), kondisi fasilitas (facilitating condition), nilai harga(price value) tidak terbukti signifikan mempengaruhi niat berperilaku (behaviour intention). Faktor kondisi fasilitas dan habit juga tidak terbukti signifikan mempengaruhi perilaku penggunaan (usage behaviour). Hal ini bertolak belakang dengan hasil dari penelitian Venkatesh 2012 yang menemukan UTAUT2. Penelitian Venkatesh 2012 dan beberapa penelitian sebelumnya pada objek penelitian yang berbeda. Hal ini mungkin disebabkan beda objek penelitian dan wilayah yang digunakan untuk responden. Beberapa penelitian UTAUT2 menunjukan hasil yang berbeda untuk objek yang sama dimana wilayah yang diteliti berbeda. Hal ini juga membuktikan penelitian Hofstede bahwa berbeda wilayah atau negara menghasilkan hasil penelitian yang akan berbeda.

Pengukuran terakhir adalah memvalidasi model dengan melihat nilai $\mathrm{R}^{2}$. Pada penelitian ini dilakukan dua kali pengukuran untuk melihat seberapa besar pengaruh dimensi budaya terhadap penggunaan aplikasi transportasi online. Penelitian ini mengujikan model UTAUT2 dan model UTAUT2 yang ditambahkan variabel dimensi budaya Hofstede. Hasil pengukuran $\mathrm{R}^{2}$ dapat dilihat pada tabel di bawah.

Tabel 5. Cronbach's Alfa, CR dan AVE

\begin{tabular}{lll}
\hline Variabel Dependent & R2 (UTAUT2) & R2(UTAUT2 + Dimensi Budaya Hofstede) \\
\hline BI & 0,768 & 0,768 \\
UB & 0,197 & 0,502 \\
\hline
\end{tabular}

Berdasarkan tabel diatas hasil pengukuran R2 pada UTAUT ditambahkan dimensi budaya Hofstede nilai untuk variabel BI sebesar 0,768 dan variabel UB 0,502. Hal ini didapatkan bahwa variabel independen yang mempengaruhi BI sebesar 76,8\% sedangkan variabel independen yang mempengaruhi UB sebesar 50,2\%. Pada hasil pengukuran R2 pada model UTAUT2 ditambah dimensi budaya Hofstede mengalami penambahan dibanding dengan model UTAUT2. Hal ini menunjukan variabel dimensi budaya Hofstede mempengaruhi variabel UB. Modifikasi UTAUT2 ditambah dimensi budaya Hofstede dapat menunjukan bahwa budaya mempengaruhi penggunaan aplikasi transportasi online. Pada model dimensi budaya langsung mempengaruhi kebiasaan penggunaan aplikasi transportasi online.

Pada penelitian ini dimensi budaya Hofstede terbukti mempengaruhi hasil dari modifikasi model UTAUT2. Berdasarkan data hasil pengukuran $\mathrm{R}^{2}$ untuk model UTAUT2 dengan menambahkan dimensi budaya Hofstede memperoleh hasil yang lebih baik untuk menjelaskan pengaruh faktor perilaku penggunaan aplikasi transportasi online daripada model UTAUT2. Hal ini menunjukan bahwa budaya mempengaruhi akan perilaku penggunaan aplikasi transportasi online. Hal ini ditambah dengan adanya dimensi budaya Indulgence Restraint (IR) yang mempengaruhi positif signifikan. 


\subsubsection{Implikasi Penelitian}

Hasil penelitian ini telah membuktikan bahwa budaya memiliki pengaruh terhadap penggunaan aplikasi transportasi online. Hal ini menunjukan bahwa budaya dapat digunakan sebagai dasar dalam membuat strategi bagi perusahaan untuk mendapatkan lebih banyak pengguna.

Perhatian terhadap budaya memang seharusnya sudah menjadi bagian dari strategi dari Perusahaan aplikasi transportasi online. Berdasarkan hasil penelitian Indulgence adalah dimensi yang signifikan dalam mempengaruhi penggunaan aplikasi transportasi online. Indulgence diartikan bahwa manusia dalam sebuah masyrakat bebas untuk mencari kesenangan sesuai dengan keinginan. Perusahaan dapat memasukan strategi pemasaran dengan menunjukan bahwa bebas untuk memilih fasilitas yang ada dalam transportasi online. Dapat juga bebas dalam memilih pembayaran serta mempermudah dalam penggunaannya. Dari dimensi budaya indulgence dapat juga mempengaruhi desain dari aplikasi transportasi online. User interface dari aplikasi transportasi online dipermudah penggunaannya dimana pengguna dapat memilih menu dengan bebas hanya menu yang disukainya.

Implikasi bagi dunia penelitian adalah hasil penelitian ini semakin menekankan dimana dimensi budaya penting dimasukan dalam setiap model penelitian penggunaan teknologi. Memasukan dimensi budaya dalam model penelitian memang perlu terutama penelitian di negara yang memiliki banyak kebudayaan dan juga di negara berkembang.

\section{KESIMPULAN}

Penelitian ini telah menunjukan dan membuktikan bahwa budaya dapat mempengaruhi penggunaan aplikasi transportasi online. Hal ini ditunjukan dengan adanya hasil prediksi perilaku penggunaan transportasi online sebesar 50,2\% dari model UTAUT2 yang dimodifikasi dengan menambahkan dimensi budaya Hofstede dibandingkan dengan Model UTAUT2. Dimensi budaya indulgence terbukti signifikan dalam mempengaruhi penggunaan aplikasi transportasi online.

Budaya dapat digunakan sebagai salah satu faktor bagi perusahaan aplikasi trasnportasi online dalam menyusun strategi pemasaran atau dalam desain aplikasi. Diharapkan dengan hasil penelitian ini perusahaan aplikasi tranpsortasi online dapat memperoleh lebih banyak pengguna.

Bagi dunia penelitian dengan objek penelitian negara dengan banyak kebudayaan dan negara berkembang sebaiknya memasukkan dimensi budaya dalam pengukuran faktor-faktor yang mempengaruhi penggunaan teknologi. Hal ini terbukti salah satunya dari hasil penelitian ini. Diharapakan dengan memasukkan dimensi budaya dapat menambah hasil untuk menjelaskan faktor-faktor yang mempengaruhi penggunaan teknologi.

\section{REFERENCES}

[1] D. Straub, M. Keil, and W. Brenner, "Testing The Technology Acceptance model accros Culture: A three Country Study.Information \&Management," Inf. Manaj., 1997.

[2] G. Hofstede and M. H. Bond, "Hofstede's Culture Dimensions," J. Cross. Cult. Psychol., vol. 15, no. 4, pp. 417-433, Dec. 1984.

[3] G. Baptista and T. O. Behavior, "Understanding mobile banking: The unified theory of acceptance and use of technology combined with cultural moderators," Elsevier, 2015.

[4] A. Marcus and E. West Gould, "Crosscurrents : Cultural DImensions and Global Web User Interface Design," 2000.

[5] Susilo, "Kegagalan Internasionalisasi MNC di Suatu Negara: Studi Kasus Kegagalan Internasionalisasi Uber di Tiongkok," journal.unair.ac.id, 2017.

[6] Tahupedia, "10 Perusahaan Startup Mengungkapkan Alasan Kegagalan Mereka," 2013. [Online]. Available: http://www.tahupedia.com/content/show/302/10-Perusahaan-Startup-Mengungkapkan-Alasan-Kegagalan-Mereka. [Accessed: 22-Feb-2019].

[7] Marketingtochina, "Why Ebay failed in China?," 2018. [Online]. Available: https://www.marketingtochina.com/ebayfailed-china/. [Accessed: 25-Feb-2019].

[8] H. Sriwindono and S. Yahya, "Toward modeling the effects of cultural dimension on ICT acceptance in Indonesia," academia.edu, 2012.

[9] G. W. England, "The Manager and His Values(Ballinger,Cambridge,MA),” 1975.

[10] Venkatesh, Thong, and $\mathrm{Xu}$, "Consumer Acceptance and Use of Technology: Extending The Unified Theory of Acceptance and Use of Technology," Mis Q., 2012.

[11] Srite and Karahanna, "The Role of Espoused National Cultural Values in Technology Acceptance," Mis Q., 2006.

[12] L. Hassan, E. Shiu, and G. Walsh, "A Multi-country Assessment of The Long-term Orientation Scale," Int. Mark. Rev., 2011.

[13] J. Hair, C. Ringle, and M. Sarstedt, "PLS-SEM: Indeed a Silver Bullet," J. Mark. Theory Appl., 2011.

[14] V. Venkatesh, M. Morris, G. Davis, and F. Davis, "User Acceptance of Information Technology: Toward a Unified View," Mis Q., 2003.

[15] Compeau and Higgins, "Computer self-efficacy: Development of a measure and initial test," Mis Q., 1995.

[16] Ajzen, "Perceived Behavioral Control, Self-Efficacy, Locus of Control, and the Theory of Planned Behavior," J. Appl. Soc. Psychol., 2002.

[17] W Yu and R. Ramanathan, "Retail service quality, corporate image and behavioural intentions: the mediating effects of customer satisfaction," Int. Rev. Retail, 2012. 
JURNAL MEDIA INFORMATIKA BUDIDARMA

Volume 4, Nomor 2, April 2020, Page 377-385

ISSN 2614-5278 (media cetak), ISSN 2548-8368 (media online)

Available Online at https://ejurnal.stmik-budidarma.ac.id/index.php/mib

DOI 10.30865/mib.v4i2.2062

[18] G. Hofstede and M. Minkov, "A replication of Hofstede's uncertainty avoidance dimension across nationally representative samples from Europe," Int. J. Cross Cult. Manag., 2014

[19] Png, I. P. L., B. C. Y. Tan, and K. L. Wee, "Dimensions of national culture and corporate adoption of IT infrastructure," IEEE Trans. Eng. Manag., vol. 48, pp. 36-45, 2001.

[20] Yoon, "The effects of national culture values on consumer acceptance of e-commerce: Online shoppers in China," Inf. Manag., 2009.

[21] G. Hofstede, G. Hofstede, and M. Minkov, "Cultures and Organizations: Software of The Mind: Intercultural Cooperation and its Importance for Survival," 2010.

[22] G. Hofstede, G. Hofstede, M. Minkov, and H. Vinken, Value Survey Module 2008 Manual. 2008.

[23] S. Haryono, Metode SEM untuk Penelitian Manajemen : Amos,Lisrel \&PLS. Luxima, 2017. 